\title{
CLIFF SWALLOWS ARE GATHERING MUD
}

\section{DAN LORAN}

Box 1064 Indian Head, SK S0G 2K0 306-695-3657

Email: drloran@sasktel.net

These Cliff Swallows are gathering mud to make their nests. Those nests are under the old cement bridge in the Qu'Appelle Valley north of Indian Head, SK (the old \#56 Highway Bridge). Photos taken Monday July 6th 2015.

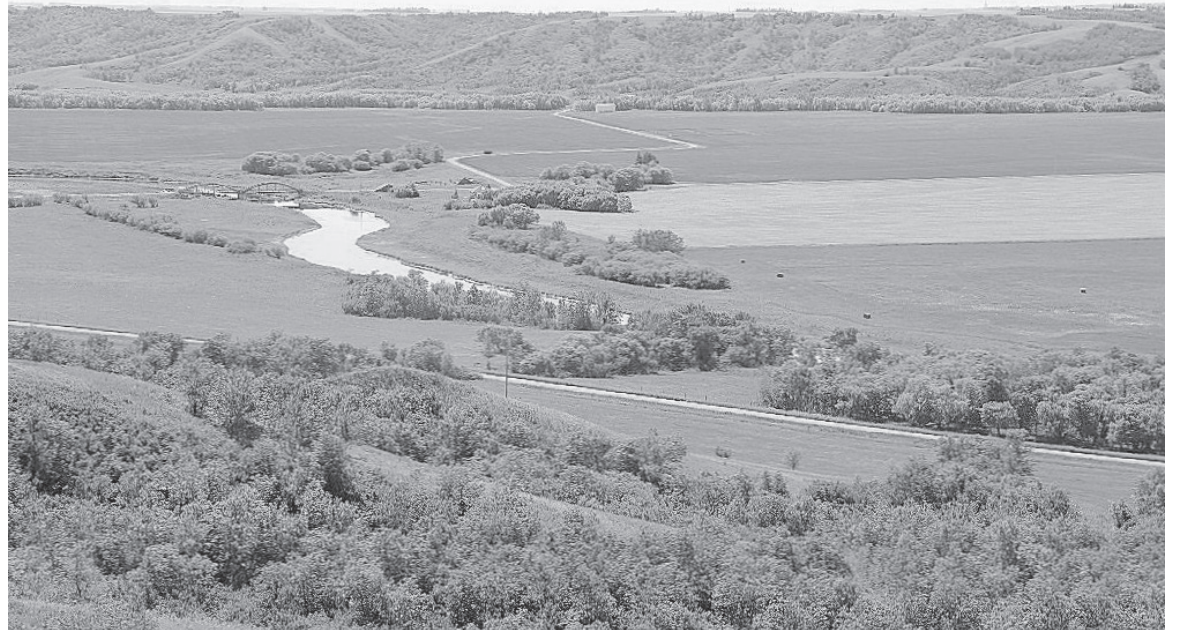

Qu'Appelle Valley

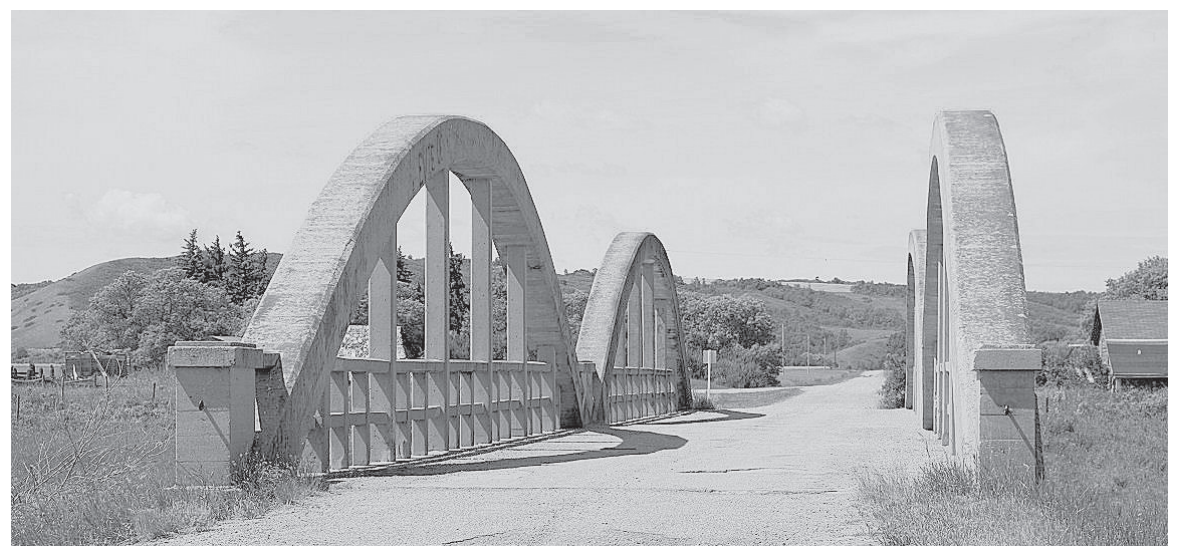

Old cement bridge - Qu'Appelle Valley 


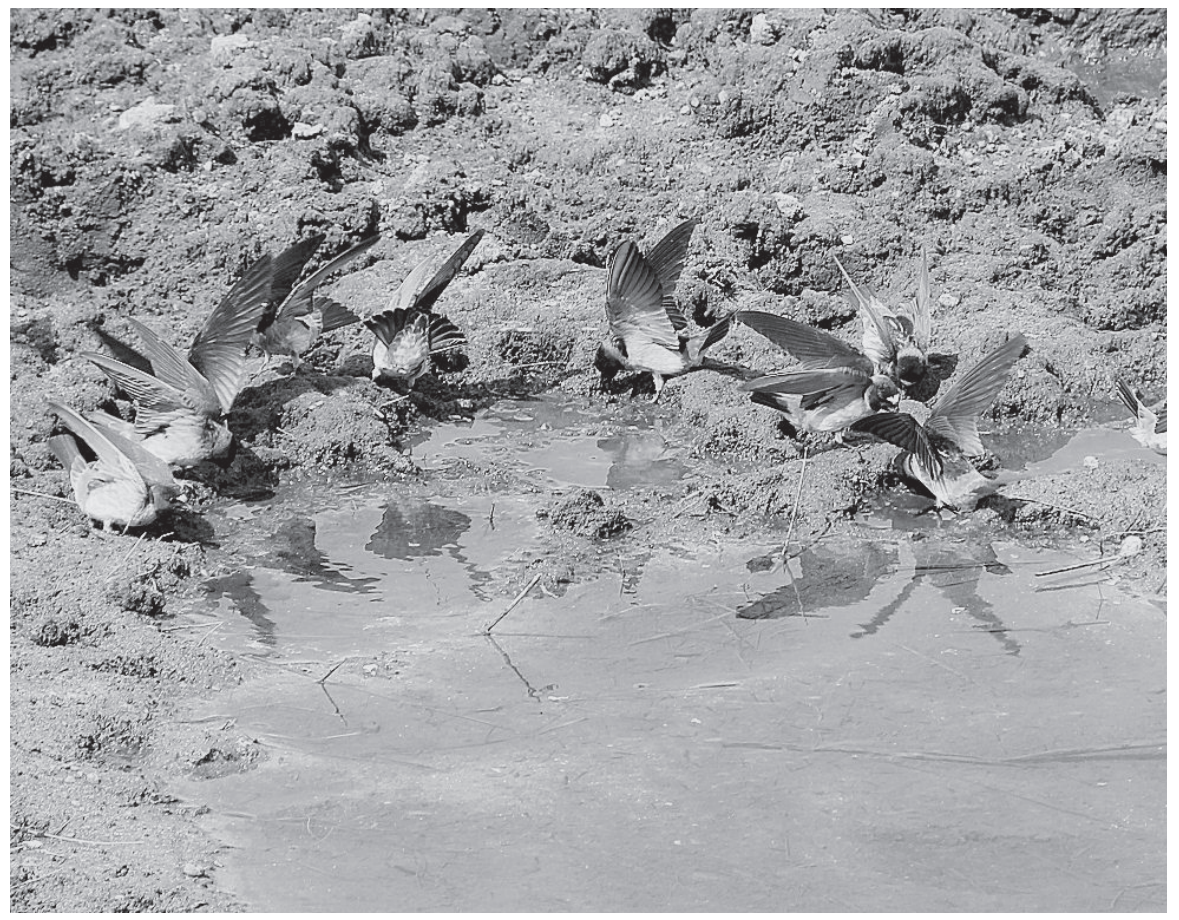

\section{Cliff swallows gathering mud}

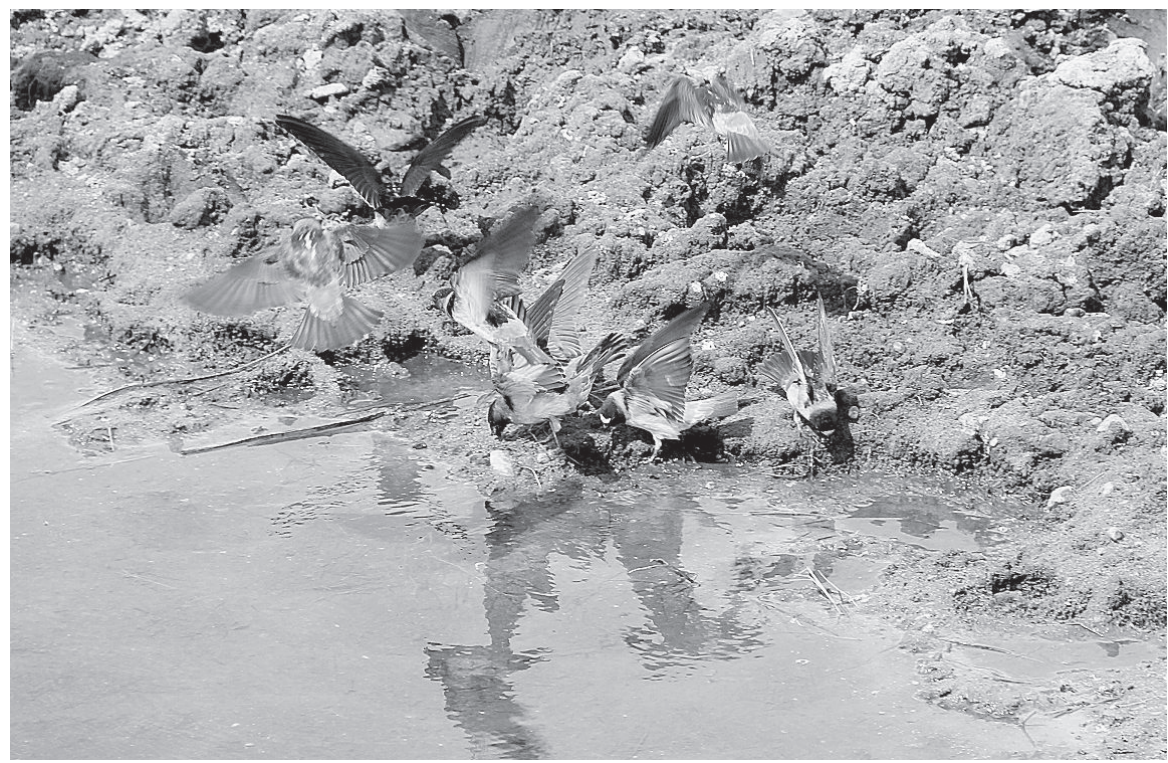

\section{Cliff swallows gathering mud}

